\title{
Exploring the attachment styles of adolescents who sexually offend: a mixed-methods research approach
}

\begin{abstract}
The literature suggests that between $20 \%$ and $33 \%$ of all sexual offences are committed by young people. ${ }^{1}$ Children and adolescents who display sexually harmful behaviour are not a homogenous group in their offending patterns or their psychosocial needs. This study used a mixed-methods approach to explore the attachment styles of adolescent sex offenders, using a typology based on victim-age. The Adolescent Attachment Style Interview (ASI$\mathrm{AD} ;{ }^{2}$ was administered to 32 young males between the ages of 12 and 19 who were convicted or alleged to have committed a sexual offence. Results suggested that adolescent sex offenders are likely to display insecure attachment styles. The results further suggested that peer abusers are more likely to display avoidant attachment styles whereas child abusers are more likely to display anxious attachment styles. The results of this study were in line with adult models of sexual offending. ${ }^{3}$ The qualitative results further suggested that adolescent sex offenders value predictability, validation, feeling an emotional bond and getting tangible support from their relationships with close others. The adolescents in this study also identified negative past experiences, person-perception processes, and negative affectivity as factors that present as relational barriers. Findings of this study suggest that the exploration of attachment relationships can be useful in discriminating the particular needs and interpersonal dynamics of child abusers and peer abusers. This has clear implications for clinical practice and policy, as it allows for the development of individualised and person-centred treatment plans.
\end{abstract}

Volume 5 Issue I - 2016

Mariana Reis
University of Birmingham, UK

Correspondence: Mariana Reis, University of Birmingham, UK, Email marianapimentareis@gmail.com

Received: December 18, 2015 | Published: January 12, 2016

\section{Introduction}

Up until the 1980's, sexual offending by children and adolescents was often minimized as "experimentation" or exploratory behavior. ${ }^{4}$ However, the research of the past few decades has indicated that adolescents who sexually offend account for a significant number of child sexual abuse perpetrators. ${ }^{5}$ The evidence suggests that between one fifth and one third of all child sexual abuse in the UK is committed by young people. ${ }^{1}$ The victims are often known to the perpetrator and can be siblings, younger children, adults, males and females. ${ }^{6,7}$

Regarding the likelihood of reoffending of this client group, research suggests that adolescents' rate of sexual recidivism is lower than that of adult sex offenders. ${ }^{8}$ A meta-analysis of treatment studies in North America found a sexual recidivism rate of $12.5 \%$ after a 5 year follow-up. ${ }^{9}$ Similarly, Richardson ${ }^{10}$ found that the mean of sexual reoffending rate was $12.4 \%$ in an international review of 59 recidivism studies. Worling, et al., ${ }^{11}$ carried out a longitudinal study and found a sexual re-offending rate of $16.8 \%$. This study is particularly significant because the follow up period, 20years, greatly exceeds the average follow up period of other studies (4-5years). The results also showed that specialised treatment for adolescent sex offenders added to significant reduction in both sexual and nonsexual recidivism. Even taking into account under-reporting issues and the difficulty of gaining accurate re-offence data, persistence of adolescent sexually harmful behaviors into adulthood is deemed to be the exception rather than the norm. ${ }^{12}$

Policies supporting young people who sexually offend have developed greatly in recent years. There is now a recognition that young people who present with sexually harmful behavior often have unmet needs in addition to their harmful behaviors. ${ }^{13}$ With this is mind, in the late 1990's, Youth Offending Teams were given the lead for young people who offend sexually. ${ }^{14}$ This multiagency structure was created with the aim of meeting young people's needs and tackling offending behaviors. ${ }^{15}$ However, research completed shortly after this introduction found that continued separate child welfare and criminal justice systems were a source of inconsistent responses to young people who sexually abuse. ${ }^{15}$ This led Hackett et al. ${ }^{16}$ to recommend that "nationally based and detailed guidance should be developed, which addresses how effective working across child welfare and youth justice systems can be achieved, both at the level of local area and at the individual case". ${ }^{16}$ These recommendations were acknowledged in $2010 .{ }^{17}$ However, so far, there is an absence of evidence that they have been implemented. ${ }^{13}$

The literature suggests that factors influencing both delinquency and sex offending behavior in adolescents include criminal history, individual, school, and family characteristics. ${ }^{18}$ The following characteristics are related to the onset of both delinquency and sexual offending behavior: age of onset of criminal behavior, early behavioral issues, school problems and dysfunctional family environments (characterised by conflict, neglect, lack of discipline, physical and sexual abuse, parental impairments, siblings antisocial behavior, low socioeconomic status and parent-child separation). ${ }^{18}$ Although family dysfunction is associated with both delinquency and sexual offending, it appears that witnessing family violence, parental physical abuse and/or sexual abuse is significantly more correlated with the emergence of sexually deviant behavior ${ }^{19-21}$ compared to its relationship with subsequent delinquency. Regarding interpersonal characteristics, it has been strongly suggested that most adolescent sex offenders have psychosocial problems, ${ }^{22-24}$ affect regulation deficits $^{25,26}$ and often display more internalizing problems than other types of adolescent offenders. ${ }^{27}$ Nevertheless, sex offenders, including adolescents, display a broad range of interpersonal characteristics and offending patterns. ${ }^{28,29}$

Several theoretical models have been proposed in an attempt to explain sexual offending behavior and the heterogeneity displayed by sexual offenders. Some studies directly examined attachment 
dynamics in sexual offenders and have found a high prevalence of characteristic attachment problems among different types of sexual offenders. ${ }^{30-33}$ Nevertheless, and as highlighted in Chapter 2, the link between different insecure attachment types and specific sub-groups of sexual offenders has not been consistently found. Therefore, the literature exploring the attachment styles of adolescent sex offenders, in particular, is also extremely limited.

The need to distinguish subtypes of adolescent sex offenders on theoretical and empirical grounds in order to inform assessment, treatment and prevention efforts has been highlighted by the literature. ${ }^{34}$ Currently, typologies of adolescent sex offenders exist based on different characteristics such as offending behaviour, victim age, recidivism or psychological characteristics. As previously mentioned, the most widely used method to explore pathways to sexual offending, including adolescent sexual offending, is a dichotomous typology based on victim age. ${ }^{35}$ For adolescents, this criterion differentiates between those who offend against children and those who offend against peers. According to most of the literature, those who offend against victims at least five years younger than themselves are categorized as 'child abusers', whereas those who offend against victims less than five years younger or older than themselves are categorized as 'peer abusers'.

One of the few studies investigating the attachment style of adolescent sex offenders using a victim age typology was conducted by Miner and colleagues in 2010. The authors compared 107 child abusers, 49 peer abusers and 122 non-sexual offenders between the ages of 13 and 18 on measures of attachment style, social isolation, perceived self-adequacy and hyper sexuality. This study found that attachment anxiety has an indirect effect on child sexual abuse perpetration and is mediated by peer isolation and anxiety towards women. In a follow-up study, Miner et al., ${ }^{36}$ compared 140 adolescent child abusers, 92 adolescent peer abusers and 93 adolescent who were in treatment for mental health or substance use problems and had no sexual or non-sexual offending history. This study used a face-to-face attachment interview ${ }^{37}$ to explore attachment styles. The results did not show a difference in attachment anxiety between child abusers and peer abusers. However, adolescent peer abusers demonstrated higher levels of masculine adequacy than child abusers. The results also suggested that sexual offending against children was associated with fewer intrusive thoughts and fantasies than sexual offending against peers. Additionally, the data indicated that sexual offending against peers/adults was unrelated to attachment, social involvement, or masculine adequacy, but was related to problems with controlling sexual behavior (sexual compulsivity).

Overall, the data presented by Miner et al., ${ }^{38}$ suggests that attachment anxiety leads to sexual offending against children, when the individual is also isolated from peers and feels anxious around women. Masculine inadequacy is also more likely to be correlated with child abuse than peer abuse. In relation to peer abusers, they are more likely to be sexually preoccupied and experience problems in controlling sexual behaviours than child abusers. These studies have a number of limitations, including employing offender categories that are not exclusive, recruiting convenience samples and not having an equal distribution between residential and outpatient participants. However, the findings about attachment anxiety and indicators of social involvement are consistent with those in adult samples ${ }^{32,39-41}$ which suggests that these variables are associated with sexual offending behaviour, regardless of age.

Despite the lack of research exploring attachment styles directly, there is a wide range of studies investigating the early experiences and interpersonal styles of adolescent sexual offenders, as well as their offending behaviors, using a typology based on victim age. For instance, ${ }^{42}$ explored the upbringing of 56 adolescent male sex offenders, controlling for socioeconomic status, age of offender and the size of the family of origin. The researchers found differences between adolescent child abusers and peer abusers who had disturbed family backgrounds. Peer abusers came from a family background characterised by a high rate of long-term parent-child separations, and committed more violent offences whereas child abusers had witnessed physical violence between their parents, were described as having been infants who did not enjoy being cuddled, and had siblings who truanted school. It was also suggested that while $72 \%$ of the child abusers had no close friends, only $32 \%$ of the peer abusers were so isolated. This would suggest that adolescent child abusers have more difficulty in forming attachments to others and are more socially isolated than peer abusers, which reflects their feelings of anxiety and inadequacy around adults mentioned by Miner et al., ${ }^{36,38}$ and Ward et al., ${ }^{3}$

Similarly, Hunter et al., ${ }^{23}$ recruited a sample of 182 adolescents with a history of sexual offending and reported that, in comparison to peer abusers, child abusers have lower self-esteem and greater social deficits. They also suggested that this group shows significantly higher levels of depression and anxiety. Accordingly, Hendriks et al., ${ }^{43}$ analyzed data from 116 male adolescents prosecuted for sexual offences in the Netherlands and found that child abusers are significantly more neurotic, have more social problems, suffer more from bullying and have a greater negative self-image than peer abusers. These results were supported by Robertiello et al., ${ }^{35}$ who suggested that child abusers have higher deficits in self-esteem, social skills and suffer more from depression than peer abusers. Finally, Gunby et al., ${ }^{44}$ examined data from 43 files from Youth Offending Teams and suggested that child abusers tend to have lower self-esteem and to be more socially isolated than peer abusers.

The data presented above seems to suggest that adolescent child abusers have more interpersonal Criminogenic needs than peer abusers. However, Worling ${ }^{45}$ studied a sample of 90 adolescents who had committed contact sexual offences and reported that both child abusers and peer abusers were similar regarding variables of interpersonal functioning and self-perception. There might be several explanations for the discrepancy in results; one of them relates to the inclusion and exclusion criteria for each study. For instance, in Worling's ${ }^{45}$ sample, all the adolescents committed contact offences whereas in Gunby et al., ${ }^{44}$ study, adolescents who committed 'handsoff' offences were also included.

Furthermore, using different methods for data collection and studying different constructs may lead to discrepancies in findings. For instance, some studies looked at file records and extracted information related to being a victim of bullying and having ageappropriate friendships or low self-esteem, ${ }^{43,44}$ whereas other studies reviewed the existing literature ${ }^{35}$ or administered standardized measures. ${ }^{47}$ Furthermore, the studies did not use the same tools to measure constructs such as self-esteem. For instance, Gunby et al., ${ }^{44}$ used clinical based assessments, Hendriks et al., ${ }^{43}$ administered a measure widely used in the Netherlands. ${ }^{46}$ Hunter et al., ${ }^{23}$ used the Child Behavior Checklist ${ }^{47}$ and the Social Self-Esteem Inventory, ${ }^{48}$ and Worling ${ }^{45}$ used the Tennessee Self-Concept Scale. ${ }^{49}$

At the behavioral level, it has been found that the differences between child abusers and peer abusers in early experiences and interpersonal styles evidenced in the literature will be reflected in dissimilar offending behaviors. The research suggests that adolescent 
peer abusers are more likely to offend against strangers, use violence in the offence and use a weapon; whereas child abusers are more likely to offend against known victims..$^{23,42,43,50,51}$ Regarding sexual recidivism, it has been found that adolescents who offend against children tend to have slightly lower sexual recidivism rates than adolescents who sexually offend against peers. However, there are higher rates of sexual recidivism among more violent and chronic adolescent offenders..$^{52}$

The fact that child abusers do not tend to use violence in their offending might be explained by power differentials. In child abuse cases, the abuser is older and presumably stronger than the victim, which might discourage the victim from showing resistance, in order to avoid further harm. Gunby et al., ${ }^{44}$ also suggested that adolescent child abusers introduce the sexual contact as part of play. This is concordant with Ward et al., ${ }^{3}$ theoretical model of adult sexual offending, where child abusers groom their victims, rather than using violence, in order to achieve intimacy.

Alternatively, the use of violence and weapons and the higher rates of sexual recidivism of peer abusers are likely to be related to hostile attitudes towards others and antisocial orientation. ${ }^{32,53}$ Adolescent peer abusers have more extensive criminal records than child abusers and the sex crimes are more likely to occur in association with other types of criminal activity. ${ }^{50}$ Moreover, Hunter et al. ${ }^{50}$ found that peer abusers use unnecessary violence and are more likely to support hyper masculine attitudes than child abusers. These findings may be associated with the fact that peer abusers are more likely to experience parental physical discipline and be part of families who are involved in criminal activity. ${ }^{44,45}$ With basis on social learning theories, the patterns shown by adolescent peer abusers might be the product of modeling parents' behavior.

The evidence presented above provides support for the premise that a typology based on victim age is helpful in distinguishing between the criminogenic needs and offending behaviors of adolescent child abusers and adolescent peer abusers. Nevertheless, there are some limitations in the adolescent sex offending literature that must be considered. Firstly, there is a paucity of studies comparing adolescents who sexually offended against children with those who offended against peers/adults. ${ }^{34}$ Furthermore, in general, studies look at adolescents who came to the attention of the criminal justice system. This may not be representative of all adolescent sex offenders because sexual offences are under-reported. Most victims of sexual assault never disclose their abuse ${ }^{54}$ and, therefore, many offenders do not come to the attention of the Criminal Justice System.

Despite its limitations, there seems to be consistent empirical evidence in the adolescent sex offending literature suggesting that adolescent child abusers differ from adolescent peer abusers, which is reflected in their backgrounds, interpersonal characteristics and offending behaviors. This is congruent with the adult sex offending literature where, in comparison to peer abusers, child abusers have higher levels of emotional loneliness, lower self-esteem and more intimacy skills deficits. ${ }^{32}$ The characteristics found in adult sex offenders are likely to be related to developmental processes that have their origins in early life experiences. Additionally, the differences in intimacy and attachment styles found among child abusers, rapists and non-sexual offenders suggest that different childhood and adolescent developmental pathways may be involved in specific sexually harmful behaviors. ${ }^{55,56}$

Nevertheless, the literature has highlighted that adolescent sex offenders have specific needs, which are different from those presented by adult sex offenders. It has been suggested that the majority of adolescent sex offender treatment continue to follow adult-oriented treatment models. ${ }^{38}$ Treatment models for adolescent sex offenders should not mirror adult sex offender treatment. In comparison to adults, adolescent sex offenders are less socially mature and their cognitive and emotional capacities are not fully developed. ${ }^{57}$ Therefore, legal and clinical interventions for adolescent sex offenders should be modified to ensure that they meet the development needs of youths. ${ }^{58-60}$

There is a relative paucity of research on the etiology and treatment needs of adolescent sexual offenders. Further research on adolescent sexual offending is of the utmost importance to inform policy and clinical practice. Adolescent sex offenders are at a key developmental stage when early difficulties are beginning to impact on their relationship skills with peers. Careful management of this client group may help to prevent dysfunctional patterns establishing into adulthood. ${ }^{30}$ Furthermore, adolescent sex offenders are considered to be more responsive to treatment than adult sex offender and do not appear to continue re-offending into adulthood, especially when provided with appropriate treatment, ${ }^{61-63}$ reinforcing the need for a strong evidence-base to appropriately address their needs.

The current research aims to add to the existing literature on adolescent sexual offending by further exploring the relationship between a victim age typology and attachment styles. Moreover, and most importantly, it aims to provide empirical support for the premise that adolescent sexual offenders are a heterogeneous group for whom treatment and policy must be tailored accordingly. The current research study used the attachment interview presented in Chapter 3 to explore the attachment style of adolescent sexual offenders. Based on Ward et al., ${ }^{3}$ theoretical model of sexual offending and taking into account the findings of the systematic literature review presented in Chapter 2, the hypotheses of this study are as follows:

1. Adolescent sex offenders are more likely to be insecurely attached than to be securely attached

2. Child abusers are more likely to display an anxious attachment style in comparison to peer abusers

3. Peer abusers are more likely to display an avoidant attached style in comparison to child abusers

These hypotheses were designed having a mixed-methods approach in consideration. A mixed-methods approach allows for the exploration of research questions at different levels of analysis. It was hypothesized that by using both quantitative and qualitative methods, the author would be able to bring together a more comprehensive account of the interaction between attachment styles and sexual offending. It was further hypothesised that qualitative data would be valuable in illustrating and further exploring adolescents' perceptions of interpersonal relationships. Finally, to the author's knowledge, there are no previous studies in the literature focusing on the attachment styles of adolescent sexual offenders using a mixed-methods design. Hence, this study aims to add to the existing literature on sexual offending by adolescents.

\section{Method}

A convergent parallel mixed-methods design was chosen to conduct this study. This method converges quantitative and qualitative data in order to provide a comprehensive analysis of the research problem. In line with this design, the author collected both forms of data at the same time and then integrated the information in the interpretation of 
the overall results. The results from one method helped develop or inform the other method.$^{64}$ Therefore, equal emphasis was placed on both quantitative and qualitative results.

\section{Sample}

The sample consisted of 32 male adolescents prosecuted or alleged to have committed a sexual offence. Sexual offences committed by these individuals ranged from 'hands-off' behaviors, such as exposure, voyeurism, the showing of pornographic material, and coercing others to engage in sexual acts, through to contact offences, including touching, penetration and intercourse. This study also used extra data from Qayum; ${ }^{65}$ Exploring the link between early attachment styles and maladaptive schemas in juvenile sexual offenders). The secondary data related to fourteen interviews that were administered and scored by Qayum ${ }^{65}$ and were used for the purpose of quantitative analyses only. Extra data was obtained to larger the initial sample size and allow for a more representative sample of the target population, improving the external validity of the study.

At time of the interview, all participants' age ranged between 12 and 19years. The mean age of participants was $15.31(S D=1.80)$ and $84 \%$ of participants were looked after children at the time of interview. Regarding ethnicity, 91\% of participants were White British, 3\% were Black, 3\% were Asian and 3.1\% were mixed raced. Individuals with severe learning difficulties or mental health symptoms were not considered as appropriate participants for this study in order to minimize the existence of confounding variables. Participants were recruited from a probation service and from community or residential specialist services for children and young people who have sexually abused. No participants dropped out of this study or withdrew their consent.

\section{Procedure}

The recruitment and data collection procedure was identical for primary and secondary data. Organizations were approached and provided with information sheets regarding the study. In total, six organizations were approached and four agreed to take part. Twelve participants were recruited from a residential specialist service for young people who sexually offend, eight were recruited from another service of a similar nature, nine were recruited from a community service dedicated to the assessment and treatment of young people who sexually offend and three participants were recruited from a probation service.

After agreeing to take part, each organization identified appropriate participants based on clinical judgment of their capacity to participate (i.e., participants who were in a period of great psychological distress were not deemed as appropriate). These participants were approached by their case workers, provided with information sheets about the study and asked whether they wanted to participate. Following participants showing an interest in participating in the study, their main carriers (someone who had parental responsibility over the young person) were approached by a member of the respective organization and provided with information sheets and consent forms. Young people were also provided with a consent form prior to taking part in the study. Participation in this study was voluntary and participants were not given any compensation or incentive for participating.

Interviews were conducted at the organizations' offices, or at a residential school, in the presence of the young person's case worker or residential worker. The interviews lasted for approximately one hour each and were all audio-recorded. For each participant, a background form was also completed by case workers or by the researcher (for secondary data). At this stage of the study, and in line with a convergent parallel design, quantitative and qualitative data were collected concurrently. With regards to the secondary data collection, it is worth noting that the risk of contamination is low, since the ASI$\mathrm{AD}$ was administered before other measures were administered.

\section{Ethical considerations}

This study was approved by the University of Birmingham Research Ethics Committee and by the appropriate organization involved in the young person's care. In order to obtain ethical approval the researcher had to consider several issues around: recruitment, consent, participants' feedback and withdrawal, compensation, confidentiality; storage, access and disposal of data; benefits and risks for participants and the researcher.

Prior to meeting with the participants, the researcher met with case workers for 10minutes in order to discuss any potential risk issues, as well as identifying the young person's main vulnerabilities. Prior to commencing the interview, all participants were debriefed about the aim of the interview (to look at how adolescents relate to people they are close to and people in general), consent, right to withdraw and confidentiality issues. Limits to confidentiality included disclosing information that raised concerns about:

1. The safety of the participants themselves;

2. The safety of other persons who may be endangered by the participant's behaviour;

3. The health, welfare or safety of any individual. All participants understood the conditions of the study and provided consent for partaking and being audio-recorded. Parental consent was also granted for all participants under the age of 18. Following these interviews, all participants were appropriately debriefed to ascertain whether they showed any signs of distress.

In terms of potential risk for participants, since the Adolescent Attachment Style Interview explores interpersonal relationships, it was possible that participants who suffered trauma, or have been part of dysfunctional families might experience distress while answering questions about their close relationships. While interviewing, the researcher was aware of this possibility, and monitored the participants' presentation closely. In case participants had demonstrated any signs of distress, the researcher would have liaised with case holders and key workers, to ensure that participants received the appropriate support. However, this was not the case and participants did not demonstrate signs of distress.

All data will be kept for 10years in line with the University of Birmingham code of Practice for Research 2012-2013. Only the researcher has access to the recording of the interviews. Raw data (including questionnaires and audio-recordings) is kept in a locked cabinet. Electronic data is only accessible by the main researcher and it is stored in a secure place (Laptop with appropriate passwords). Codes and names are kept in a separate place.

\section{Measures}

\section{Adolescent Attachment Style Interview}

Participants were administered the Adolescent Attachment Style Interview (ASI-AD). ${ }^{2}$ The ASI-AD was the main source of qualitative data. This measure is an adaptation of the Attachment Style Interview (ASI). ${ }^{66}$ As mentioned in Chapter 3, the ASI is a semi-structured interview tool which assesses attachment styles in adults, based 
on the quality of ongoing close relationships and general attitudes towards others. The seven attitudinal scales are scored to determine attachment avoidance (e.g., mistrust, constraints on closeness, selfreliance and fear of rejection) or attachment anxiety (e.g., desire for closeness, fear of separation and anger).

The ASI differentiates between the following attachment styles: Secure (the most adapted), Insecure Anxious (Enmeshed or Fearful), Insecure Avoidant (Angry-dismissive or Withdrawn), and Insecure Dual/disorganized (Anxious and Avoidant). An additional classification of degree of insecurity is made, based on the extent to which behavior and attitudes in relationships are dysfunctional. Within each insecure attachment style individuals can be assessed as 'marked', 'moderately', or 'mildly' insecure.

The ASI-AD is identical to the ASI in content and structure. However, slight modifications have been made in order to make the measure more relevant for an adolescent sample. These adjustments include: allowing the adolescent to choose a 'parent/main carrier' as the main attachment figure rather than a partner; allowing young people to choose individuals under the age of 18 as 'Very Close Others'; and the life events list has been changed to reflect experiences more relevant to young people.

\section{Background form}

For primary data, the participants' case workers were asked to complete a background form (Appendix 12) which was composed of several demographic variables, information on offending history, family background and aspects about the offenders' victims such as age, relationship to offender and offence type. The background form of the secondary data included the following: ethnicity of offender, category of offender (child abuser/ peer abuser) and type of sexual offence. The background forms were the main source for quantitative data.

\section{Quantitative Data Analysis}

The information from the background forms was used to categorize participants as 'child abusers', 'peer abusers' or 'cross-over' group, based on the age of the victim relative to the perpetrator. Those who offended against a victim less than four years younger, or older than themselves, were termed as 'Peer abusers'. Those who offended against victims at least four years younger than themselves were termed 'Child abusers' (e.g. 19 year old offending against a 15year old victim). A threshold of four years was used in order to be concurrent with the secondary data. Participants who offended against 'peers' and 'children' were included in the 'Crossover group'. Of note is the fact that categorisation of sexual offenders was reliant on official records and/ or self-report. This means that offenders that were categorised for instance as child abusers, may have previously committed sexual offences against peers/adults, that have never been reported and hence are not reflected in official records.

Attachment styles found through analysis of the ASI-AD interviews were further coded, as well as all the variables from the background forms. All quantitative data were analysed by the author of this study using IBM SPSS Statistics 22 software and Microsoft Excel 2010. Preliminary analyses were conducted to obtain descriptive statistics for the categorical variables.

\section{Qualitative Data Analysis}

An initial qualitative analysis of all interview transcripts was made according to the ASI-AD manual. ${ }^{2}$ The author of this study conducted and scored all the interviews related to the primary data $(n=18)$ and Qayum ${ }^{65}$ conducted and scored all the interviews related to the secondary data $(n=14)$. This analysis allowed for a categorization of attachment styles (Secure, Anxious, Avoidant, Dual) and insecurity degree (mild, moderate, marked) which was then used to inform the quantitative analysis. Scoring of the ASI-AD interviews was performed blind to offender status (child abuser, peer abuser, crossover) for both primary and secondary data, in order to control for confirmation bias.

Twelve interview scripts from the primary data $(n=18)$ were then analyzed using the 'Framework approach'. Six transcripts were excluded at this stage, due to limited information (i.e. participants responded with yes or no answers). The interviews from secondary data were not considered for analysis using the 'Framework approach' because the author could not access the full transcripts. The Framework approach was developed during the 1980s at the National Centre for Social Research ${ }^{67}$ and it draws on many different traditions within qualitative research and the social research field. The name 'Framework' comes from the 'thematic framework' which is the central component of the method.

The different stages of the 'Framework approach' are as follows:

1. Familiarization with the data, achieved by listening to audiorecordings, transcribing and reading the transcripts in their entirety several times.

2. Classifying and organising data according to key themes, concepts and emergent categories, using a thematic framework.

3. Indexing, achieved by analysing recurrent themes and sub-themes, making comparisons between and within cases, highlighting quotes and labeling transcripts.

4. Charting, achieved by lifting the quotes from their original context and re-arranging them under the newly-developed themes.

5. Mapping, achieved by creating a matrix where each main theme is displayed in its own matrix, every respondent is allocated a row and each column denotes a separate subtopic. ${ }^{67}$

6. This qualitative method was chosen mainly due to its combined approach to analysis, enabling interpretation of data on both a thematic and a single-case basis. It was deemed as vital to employ a qualitative method that allowed exploration of single case narratives, in order to contextualize specific offending behaviors in a broader attachment-related thematic framework. Additionally, this approach was chosen as it employs a rigorous and transparent data management criterion and encompasses both deductive and inductive data analyses processes.

\section{Qualitative process}

The first stage of the qualitative process was transcription and familiarization with the data. Interviews were transcribed verbatim. In line with the guidelines for transcribing ASI interviews, the author was interested in the content, rather than the structure of participants' responses for analysis. Only long pauses, interruptions and nonverbal communication (such as nodding) were noted within the text. All transcripts were checked for errors by listening back to the audiorecording and reading the transcripts simultaneously. Each transcript was supplemented with notes made during and immediately after the interview, including important contextual and demographic information. Familiarisation with the data was achieved by listening to the audio-recordings and reading the transcripts several times.

In the coding stage, initial impressions were recorded in the margins of transcripts, interesting quotes were highlighted and different types 
of information were listed. Remarkable parts of the data were coded in a way that offered a description of what each segment in the text related to. This was followed by indexing all initial codes and initial thoughts, organising these in to sections, and categorising themes and sub-themes (please find indexing table in appendix 13). These were revised and refined several times until final themes and sub-themes emerged, which were then used to label the transcripts. The charting process can be found in appendix 14. Once all the data had been coded using the analytical framework, it was summarised in a matrix for each theme using Microsoft Excel. As illustrated in appendix 15, the matrix comprised of one row per participant and one column per code. Diagrams illustrating the relationships between themes and subthemes can be found in appendix 16 .

\section{Measures}

\section{Adolescent Attachment Style Interview}

Participants were administered the Adolescent Attachment Style Interview (ASI-AD) ${ }^{2}$ The ASI-AD was the main source of qualitative data. This measure is an adaptation of the Attachment Style Interview (ASI). ${ }^{66}$ As mentioned in Chapter 3, the ASI is a semi-structured interview tool which assesses attachment styles in adults, based on the quality of ongoing close relationships and general attitudes towards others. The seven attitudinal scales are scored to determine attachment avoidance (e.g., mistrust, constraints on closeness, selfreliance and fear of rejection) or attachment anxiety (e.g., desire for closeness, fear of separation and anger).

The ASI differentiates between the following attachment styles: Secure (the most adapted), Insecure Anxious (Enmeshed or Fearful), Insecure Avoidant (Angry-dismissive or Withdrawn), and Insecure Dual/disorganized (Anxious and Avoidant). An additional classification of degree of insecurity is made, based on the extent to which behavior and attitudes in relationships are dysfunctional. Within each insecure attachment style individuals can be assessed as 'marked', 'moderately', or 'mildly' insecure.

\section{Results}

\section{Quantitative Results}

Descriptive statistics: The sample was composed of 32 participants: 16 child abusers, 9 peer abusers and 7 who belonged to the crossover group. In terms of the most serious offence committed by the participants, 27 committed sexual assault, 2 committed buggery, 2 committed exposure and 1 committed voyeurism.

Regarding attachment propensities, 9\% of participants displayed a secure attachment style, in comparison with $91 \%$ who displayed an insecure attachment style. More specifically, $9 \%$ of participants displayed a secure attachment style, $41 \%$ displayed an anxious attachment style, $28 \%$ displayed an avoidant attachment style and $22 \%$ displayed a dual/ disorganized attachment style.

As presented in Table 1, the data indicate that $56 \%$ of child abusers displayed an anxious attachment style, in comparison to $22 \%$ peer abusers displaying this same attachment style. Furthermore, $67 \%$ of peer abusers displayed an avoidant attachment style, in comparison to $13 \%$ of child abusers displaying this same attachment style.

Descriptive statistics and the graph below (Figure 1) seem to support the hypotheses of this study (Adolescent sex offenders are more likely to be insecurely attached than to be securely attached; Child abusers are more likely to display an anxious attachment style in comparison to peer abusers; Peer abusers are more likely to display an avoidant attached style in comparison to child abusers).

Table I Attachment Style per Offender status ( $N=32)$

\begin{tabular}{lllll}
\hline & Secure & Anxious & Avoidant & Dual/ Disorganized \\
\hline Child Abusers & $12 \%$ & $56 \%$ & $13 \%$ & $19 \%$ \\
Peer Abusers & $0 \%$ & $22 \%$ & $67 \%$ & $11 \%$ \\
Crossover & $14 \%$ & $29 \%$ & $14 \%$ & $43 \%$ \\
\hline
\end{tabular}

Table 2 Characteristics of the twelve participants whose interviews were qualitatively analysed

\begin{tabular}{|c|c|c|c|c|c|}
\hline Name & Age & Offender Status & Attachment Style & \multicolumn{2}{|c|}{ Type of Residence Vco's Chosen } \\
\hline Michael & 15 & Crossover & Avoidant & Residential & Staff members \\
\hline John & 14 & Peer abuser & Anxious & Residential & $\begin{array}{l}\text { Grandmother/ social worker/ staft } \\
\text { member }\end{array}$ \\
\hline Terry & 16 & Peer abuser & Avoidant & Residential & Father/ friend/ staff member \\
\hline Sam & 19 & Child abuser & Dual & Residential & Friends \\
\hline David & 14 & Child abuser & Secure & Residential & Sister/ friend/ staff member \\
\hline Peter & 14 & Child abuser & Dual & Residential & Staff members \\
\hline Brian & 13 & Crossover & Anxious & Residential & Staff members \\
\hline Jack & 19 & Crossover & Anxious & Residential & Staff members \\
\hline Rich & 18 & Child abuser & Dual & Residential & Mother/ staff members \\
\hline Paul & 16 & Child abuser & Anxious & Residential & Godmother/Aunt/ staff member \\
\hline lan & 16 & Crossover & Dual & Residential & Partner/ Friend/ Staff member \\
\hline Nathan & 16 & Crossover & Dual & Residential & Mother/ Brother/ Staff member \\
\hline
\end{tabular}

Table 3 Main Themes and Sub-Themes of Qualitative Analysis

\begin{tabular}{ll}
\hline Themes & Sub-Themes \\
\hline & I.I Tangible support \\
I. Relational goals & I.2 Predictability \\
& I.3 Validation \\
& I.4 Emotional bond \\
& 2.1 Negative past-experiences \\
& 2.2 Person-perception \\
I. Relational barriers & 2.3 Negative affectivity (self-directed) \\
& 2.4 Negative affectivity (self-others interactions) \\
\hline
\end{tabular}


Inferential statistics: Inferential statistics were performed to test hypotheses 2 and 3 - Child abusers are more likely to display an anxious attachment style in comparison to peer abusers; Peer abusers are more likely to display an avoidant attached style in comparison to child abusers.

A $2 \times 2$ chi-square was computed in order to test whether there was a relationship between offender status (child abuser vs. peer abuser) and attachment style (anxious vs. avoidant). Participants who displayed a secure or dual/ disorganized attachment style and participants who offended against peers and children were excluded from the analyses (13 participants were excluded). The chi-square was computed for the remaining 19 participants who abused against children or peers, and displayed an anxious or avoidant attachment style.

The chi-square test for independence indicated a significant relationship between offender status and attachment style, Fisher's Exact Test $(n=19), p<.05$. The Fisher's exact test was computed because there was an expected count of less than 5 in 2 cells. The effect size of this statistical test was also calculated, and the results found a large effect size (6). The results suggest that there is a relationship between abusing against peers or children and displaying an avoidant or anxious attachment style.

According to the descriptive and inferential statistics, it seems to be the case that peer abusers are more likely to display avoidant attachment styles and child abusers are more likely to display anxious attachment styles, supporting hypotheses 2 and 3 of this study.

\section{Qualitative Results}

Twelve interviews were analysed using the Framework approach Please refer to Table 2 for more information about the participants whose interviews were analysed. The qualitative process described in the methods section was influenced by the original research objectives and by new concepts generated inductively from the data. It allowed the author to illustrate the main focus of this study: Exploring the attachment styles of adolescents who sexually offend. By undertaking case analyses it was also possible to illustrate how different attachment styles influence adolescents' discourse and presentation.

The 'Framework approach' allowed for the identification of two main themes: Relational Goals, and Relational Barriers (Table 3). These themes were identified following from an indexing, charting and mapping process, as described in the methods section.

Theme 1: Relational goals: Participants talked about relationships as means for meeting the following needs: Tangible support, Predictability, Validation and Emotional Bond. These sub-themes were not evident across all the interviews and different participants seemed to place more emphasis on specific relational goals.

Tangible support: Eight of the twelve participants described relationships as a source of practical, instrumental support. This level of support was denoted by lack of a strong emotional bond, and confiding of only limited information. Michael stated, "I would tell him a fair bit. Not a lot, just enough for him to be in the picture." and described his relationship with one of his 'very close others' (VCO) as easily replaceable: "It would be easy to find someone else to rely on. If she wasn't there it would be the same." Of note, are David and Rich's comments: "As much detail as they need to know", "He already knew about that" which seem to imply their understanding of confiding as an information-giving process, where there is no need to talk about an issue if the other person is already aware of it.

Predictability:Eight of the twelve participants reported confidence in the fact that their VCOs were there for them if/when they need them, and made reference to this quality of the relationship as important to them: "It's good to have one person that you know is gonna be there and you know she is gonna stick by you" (Jack), "He is there when I need him", "She is always on my side, no matter what." (Rich). This relational goal was also described by the participants in relation to expectations regarding the other person, and being able to anticipate how they will act: "If I am not talking to him, he knows I am not ok" (Sam), "They will be back any minute" (David).

Validation: Most participants spoke about this relational goal at length. There were two aspects to this sub-theme that have been noted. One related to participants valuing feeling listened and understood in their relationships with others: "She is quite an understanding person, and supportive." (Terry); "We considered one another's opinions and what was going on." (Sam); "She actually listens, which is really good. She won't judge me." (Jack).

The other aspect related to participants feeling angry or having arguments in relationships when they did not feel heard, understood and supported by the other person: "Sometimes if they are not listening to me, or being rude to me." (Michael); "Sometimes I feel that some people treat me as a child still, and I absolutely hate it." (Sam); "If I feel she is critinizing me I get angry (...) People don't take me seriously." (Jack); "When he social worker doesn't tell me what's going on with me.” (Ian).

Emotional Bond: Some participants described the emotional aspect of relationships. This quality of relationships related to a level of perceived connectedness between the participant and the other person. Perceived emotional connection to VCOs also influenced participants' attitudes towards separation from them. For instance, Jack described a strong emotional bond with a VCO, which was then reflected in intense anxiety when separated:

It is quite unique. It is like a mother and son relationship. She is the only person in the home that knows everything about me. Without Mary there is no me. I felt that she abandoned me when she went to work

abroad for six months. It was hard (...) I always wonder where they are when separated from VCOs. And sometimes I panic (...) It all falls to pieces.

Finally, some participants described emotion regulation as a relational goal related to feeling an emotional bond with the other person: "Makes me feel more comfortable (...) we have our friendship so we rely on that (...)" (Sam); "He helped me manage my feelings. He comforts me in a way" (Peter).

Theme 2: Relational barriers: All participants made reference to the existence of internal constraints in interpersonal relationships. For instance, Brian described how "there is just something (...) I have got to trust them. If I can't trust them I won't do anything" and Jack stated "I don't really trust anyone (...) It is difficult to ask for help (...) There is quite a few people I wouldn't go to for help. I just never allowed them to get close to me."

Negative past experiences: Nine of the twelve participants mentioned how they found it difficult to trust people and get close to people because they had negative past experiences in interpersonal relationships. This is illustrated, for instance, by the following statements "Just because sometimes I have trusted people and they let me down so I am a bit reluctant to trust people" (John), "I haven't been able to trust people on my past" (Peter), "People have let me down before. In quite a lot of occasions" (Rich), "I have always been like that not able to trust people account of his views on trusting people. Because people have let me down before" (Nathan). Jack also provided a rich: 
Just I always live in fear because you put your life in other people's hands. It is so hard to trust people because I have been so let down. You always feel you're being plotted against. It has been the case numerous times in the past.

Person-perception: Nine of the twelve participants mentioned different processes they use to form impressions of other people. Most further mentioned acquaintanceship as an important factor when forming their opinion of others: "Only trust people I got to know for a space of time" (Peter), "It would take a little while to trust them because I need to know who they are and if I can rely on them" (Brian), "I've known them for a certain amount of time and I know if I can trust them or not" (Ian). Jack, Paul and Nathan expressed more generalized negative views of people. For instance, Jack mentioned: "No, I just don't trust people in general because even your friends might stab you in the back. It is just best not to trust people".

Negative affectivity (self-directed): Five of the twelve participants referred to self characteristics that present as an obstacle for them to form close relationships with others. Sam explained: "I have trust problems. I am an odd character in a way. I have anxiety levels so I find it difficult to socialize." which suggests a level of insight into the difficulties he experiences in interpersonal relationships. Jack stated "Yes, very difficult to get very close. Because I raise a mask a lot of the time. I don't want people to see the real me." which seems to suggest that he sees himself as defective.

Negative affectivity (self-others interactions): Eleven of the twelve participants expressed a level of discomfort and negative effect in interpersonal relationships. Most participants said that when they spend time alone with their VCOs it is at times "awkward". More generally, participants talked about feeling uncomfortable in the context of social interactions: "I just feel like it's not right. I might not feel comfortable with that" (Michael); "Most of the times I am not good at having other people telling me their problems. I do listen but..." (John). Other participants also described how they manage these uncomfortable feelings. For instance, Jack said "I just push them people in general away. Sometimes it is too much".

Overall, the qualitative thematic analysis seems to suggest that adolescent sexual offenders perceive attachment relationships to be equitably rewarding and challenging. The twelve participants mentioned above described relationships as a source of validation and support but also talked at length about the struggles they face in interpersonal relationships. This is likely to be reflective of interpersonal deficits and feelings of inadequacy around others, as suggested by the broader literature.

\section{Case analysis}

A case analysis was conducted in an attempt to illustrate the hypotheses of this study. Four participants were chosen: a securely attached participant (David), an avoidantly attached peer abuser (Terry), an anxiously attached child abuser (Paul) and a participant who abused against peers and children and displayed a dual/ disorganised attachment style (Ian).

David (14 year-old, Securely attached): At the time of interview, David was placed in specialist residential care for young people who display sexually harmful behaviour. Regarding his background history, David's biological parents had an alcohol dependency and his biological mother was sexually abused as a child. David suffered emotional abuse and neglect. He never committed a non-sexual offence. David has been convicted for sexual assault against a 7yearold female, who was the grandchild of his foster parents.
The ASI-AD interview identified David as securely attached. David expressed feeling comfortable with interpersonal relationships. He described confiding in his VCOs: "I would tell her anything", "I just speak to him about how I feel and stuff. Things I worry about (...) I just tell him and he makes me feel more happy", "When I am upset I just speak to him", and did not express any unhelpful attitudes towards others. David revealed appropriate levels of trust, no constraints on getting close to others : "When I got in the new school I went around, made new friends, it's quite easy", no fear of rejection and appropriate levels of self-reliance : "I like to have my own opinion and other people giving me advice". He also revealed appropriate levels of desire for company and fear of separation, and low levels of anger: "Only a couple of times over silly things. I sometimes go to my room. I always feel that I am listened to, if I say it in the right manner". Regarding the themes present in David's interview, he identified predictability, validation and emotional bond as important relational goals for him. David did not present with strong relational barriers, which supports his attachment security. This example illustrates the absence of attitudes denoting anxious or avoidant attachment propensities.

Terry (16year-old, Avoidantly attached): At the time of interview, Terry was placed in specialist residential care for young people who display sexually harmful behaviour. He has been diagnosed with high functioning Asperger's syndrome. Regarding Terry's background history, his biological mother had an alcohol and drug dependency and suffered from depression. She was also diagnosed as personality disordered. Terry suffered emotional abuse, physical abuse and neglect. His offending history includes theft and was alleged to commit four sexual offences. All his alleged victims were peers. Terry was alleged to have sexually abused his 13year-old half-sister for 16 months. He was also accused of stealing underwear and of using it for masturbatory purposes, and to have exposed himself to a 15yearold female acquaintance from school.

The ASI-AD interview identified Terry as avoidantly attached. Terry reported "I'll tell him Something I thought he may need to know. Sometimes I just mention it." which shows an avoidance in confiding. He also mentioned "I quite liked it when she was there", suggesting that he values the predictability and availability of others. However, there is poor evidence of actual confiding. Terry also described how not feeling validated can trigger anger: "Sometimes he doesn't quite listen what I am trying to say (...) Being treated like a little kid sometimes (...) Being looked after all the time". The following statement "I find it quite nice to have people around me. It makes you feel quite accepted" also highlights Terry's need for connectedness with others.

Terry further mentioned acquaintanceship as an important factor in forming a judgment about others. He also acknowledged an underlying fear of rejection:

Sometimes it might take a while to get very close to others. I would like to get to know them first. It is quite hard to make a judgment if you don't know the person. If I get to know the person quite well I am not afraid they will reject me.

He further expressed some negative emotionality triggered by social interactions: "Sometimes I feel a bit crowded". Other statements that illustrate his avoidant dynamics are as follows: "I just tell people to go away", "I prefer to be on my own", "Sometimes talk about it or stay away, get some separation".

Paul (16year-old, Anxiously attached): At the time of interview, Paul was placed in specialist residential care for young people who display sexually harmful behaviour. Paul has been in care since one 
and a half years old. He has been diagnosed with 'Unsocialized conduct disorder' (Code F91.1 of ICD-10). ${ }^{68}$ Regarding Paul's background history, his biological mother suffered from depression. Paul suffered physical abuse. He has a non-sexual offending history of assault without injury. Paul was alleged to sexually abuse a 6 yearold male stranger.

The ASI-AD interview identified Paul as anxiously attached. Paul reported high levels of emotionality in his relationships with VCOs:

She constantly rings up to check if I am alright and keeps open communication (...) She is the only person I can talk to (...) She's always there (...) She is always thinking about me (...) She always lets me speak first. We won't end the conversation until I feel that I am listened to and cared for (...) It's some sort of like this magical spark. It's extremely fun, it's joking, relaxed. (...) She knows me. (...) I think I would feel very alone, very scared, very lost if she wasn't there for him.

These statements describe a strong emotional bond, followed by intense separation anxiety if the other person could not be there for him. It also highlights that Paul values the predictability and validation this relationship provides him. Noteworthy is the fact that Paul also expressed extreme separation anxiety in relation to the other VCOs: "It's just such a long wait. Even if they're just away for a couple of days. I worry about their safety.", "It would be very, very hard. It would be very awful".

Paul's interview highlighted several relational barriers that are closely linked with anxious attachment propensities. He reported how negative past experiences have affected him: "I think because I have been let down so many times before and automatically I meet someone and I'm judging them straight away because of the past" and described person-perception mental process:

They can talk behind your back and be really kind to you but then behind your back they can be really nasty. Sometimes I do back away from people because you don't know them enough yet. You need to know more about them.

Paul further described intense negative affectivity triggered by social interactions:

1. It's just panic. If I get too close then what are they gonna do? When you're too close to someone, you're the most vulnerable then so it's easier for them to hurt you.

2. Overall, Paul's discourse suggests a tendency for idolisation in close relationships, which might reflect his underlying social isolation and need for intimacy and closeness. He also expressed extreme separation anxiety and fear of rejection.

Ian (16year-old, Dual/ disorganised attachment): At the time of interview, Ian was placed in specialist residential care for young people who display sexually harmful behaviour. He has been diagnosed with 'Other mixed disorder of conduct and emotions' (Code F92.8 of ICD10). ${ }^{68}$ Ian's parents had a drug dependency and Ian suffered physical and emotional abuse and neglect. He also suffered sexual abuse by his grandfather. He has a non-sexual offending history of robbery, assault without injury and drug offences. Ian was convicted of attempted rape of his 12 -old brother. He was also alleged to sexually assault a 4yearold female acquaintance and a female cousin

The ASI-AD interview suggested that Ian has a dual/ disorganised attachment style. Ian reported some avoidance in interpersonal relationships, which is noted by limited confiding: "He knows about that anyways", "If I wanted to speak to him about something, if I wanted to, I would expect him not to tell anyone else.", "I wouldn't go to him but if I wanted to talk to him about it I could" and discomfort in social interaction: "It's a bit crowded and loud and annoying". The former statements also highlight that Ian values the predictability and availability of his VCOs.

Concurrently, Ian reported anxious attitudes towards relationships. Talking about his partner, Ian said the following when asked how it would make him feel if they could not be together anymore: "I would probably not be around long pause if you know what I mean long pause". He further said the following in relation to separation from VCOs: "I worry a lot because I wonder what they're doing and I wonder what they think I am doing. I do worry really a lot. Really upsetting." Ian also made reference to negative past experiences and reflected on the impact of these experiences:

1. I've been let down by a lot of people. Pretty much my whole family and because of that it takes me a while to trust people and get to know people because I'm mostly caged in and bottle things up.

2. The statement above further suggests a negative view of self, characteristic of anxious individuals, which is further supported by the following statement: "Because of some insecurities of mine it takes me a while to figure them out".

${ }^{1}$ Participants' names have been changed to preserve anonymity.

\section{Discussion}

The mean score of the questionnaire showed that the participants have medium level $(61.8 \%)$ in total components of readiness to provision mental health services within primary healthcare facilities. (62\%) medium level in Attitudes towards mental health $(66.6 \%)$ medium level in Skills and information about mental health; also (56\%) low level in Possibilities to provide mental health services; $(56 \%)$ low level in Support and supervision and (69\%) medium level in training.

Integration into primary health care, requires investment in the training of staff to detect and treat mental disorders. Within the context of training, primary health care workers may be uncomfortable in dealing with mental disorders. ${ }^{15}$

Recent research in Salfit district in West-Bank of Palestine showed that two third of them have never received any training while $28 \%$ had been exposed to training sometimes, also that many health workers do view their training as not adequate neither organized enough. ${ }^{16}$ Some research showed that Primary care providers' have a negative attitudes toward individuals suffering from mental disorder ${ }^{17}$ and others research's findings showed that the doctors have positive attitudes towards mental health services general. ${ }^{18}$ The negative attitudes towards mental health likely to be due to the lack of information in the field of mental health, or due to misinformation and distortion. ${ }^{19}$

The results showed that; there is significant statistical differences of odds ratio $(\alpha=0.05)$ was observed in the relationship between level of GPs readiness to provide mental health services within primary health care facilities and; District, experience in mental health and training received variables. But showed that there is no significant statistical differences of odds ratio $(\alpha=0.05)$ was observed in the relationship between level of GPs readiness to provide mental health services within primary health care facilities and Sex, work experience and place of study variables.

Also some researchers showed that; there was no statistical relationship between the attitude towards mental illness among 
relatives of a mentally ill individuals and their age, sex, place of residence and education ${ }^{20}$ and others research showed the opposite. But in-service training, is also important because all health care, changes as new research and practice produces new knowledge and ways of treating disorders. The effects of training are nearly always short-lived if health workers do not practice newly learnt skills and receive specialist supervision over time. Ongoing support and supervision from mental health specialists are essential. ${ }^{1}$ Training and supervision for primary care practitioners help them to gain skills that enable greater competence and autonomy in managing mental disorders. ${ }^{8}$

Also the participants highlighted many obstacles facing them during their intervention with people who suffering from mental disorders: $31.3 \%$ lack of experience, information, training and skills related to mental health; ${ }^{21-24}$ and $30.2 \%$ work place are not suitable to provide mental health services, the large numbers of patients and not available time; $15.6 \%$ stigma and social concepts about mental health is main obstacles to provide mental health services; ${ }^{25-30} 6.4 \%$ lack of psychotropic medications; and $17.5 \%$ reported different obstacles such as; lack of team; lack of security; lack of interesting from stakeholders about mental health; lack of supervision form the psychiatrist on GPs; difficulties related to referral system for mental health services; lack of clear protocol for intervention with people who suffering from mental disorder in primary health care. ${ }^{31-36}$

Also $81 \%$ of respondents reported (yes) about; the needs to provide mental health services within primary health care facilities, and 19\% of respondents reported no. The participants who answer yes, they mentioned many reasons, the most frequent was, ${ }^{37-41} 27 \%$ there's a lot of people needs mental health services, $20 \%$ reported that; mental health and public health are linked and integrated each other, $12 \%$ for prevention through early detection, $12 \%$ to make mental health services available and more accessible, $10 \%$ because of bad conditions for Palestinian population, $7 \%$ because primary health care is the first level of contact individuals, $7 \%$ to fight stigma towards mental health and raising awareness, $4 \%$ because physical illness causes mental disorder, $1 \%$ to gain new skills for intervention with mental illness. ${ }^{42-48}$

Integration mental health into primary health care requires skills, training to address the overall reluctance of primary health care workers to work with people with mental disorders. ${ }^{49-54}$ The issue of availability of time also needs to be addressed. In many countries primary health care staffs are overburdened with work as they are expected to deliver multiple health care programs. ${ }^{55-58}$ Adequate supervision of primary care staff is another key issue which needs to be addressed if integration is to succeed. Furthermore the absence of a good referral system between primary and secondary care can severely undermines the effectiveness of mental health care delivered at primary health care level. ${ }^{59-61}$ Finally, adequate working conditions, payment, resources and support to carry out demanding work. ${ }^{15} \mathrm{~A}$ World Health Organization recommended to integrate mental health into general health care to tackle mental disorders and associated disability, but there are many barriers facing provide mental health care in primary health; $; 2,63$ lack of trained health care providers, uncomfortable feeling in dealing with mental disorders, overburdened to deliver multiple health care programs, inadequate supervision of primary care staff and lack of human resources. ${ }^{14}$

\section{Conclusion}

This study's main limitations relate to the small sample size and the sampling method. Despite efforts to obtain a larger sample size by using both primary and secondary data, the final sample size was still limited. As such, the results of this study are only tentative and are not representative of the UK population of adolescent sexual offenders. Furthermore, this study recruited a convenience sample of adolescent offenders from multiple settings and collated data from those who agreed to participate. This creates potential volunteer bias that we cannot measure. Random sampling would have been desirable. However, due to ethical and practical issues specific to the target population, using this method was not feasible. It is also worth noting that this study used a four-year threshold between the age of the victim and the age of the perpetrator to categorize offenders as child abusers or peer abusers. Different thresholds have been used in the literature (e.g. Miner et al., ${ }^{36,38}$ used a three-year threshold and Stevens et al., ${ }^{7}$ used a five-year threshold) and this may have further impacted on the results obtained.

Regarding demographics, $84 \%$ of participants were looked-after children (LAC) at the time of interview. The high proportion of LAC in the present study may have negatively skewed the results. The research suggests that, amongst others, LAC are more likely to have been physically and sexually abused, neglected and to have experienced disrupted attachments than non looked-after children. Looked-after children are also several times more likely to have poor educational outcomes and higher incidence of mental health difficulties when compared with children in the general population ${ }^{81-84}$ further suggested that looked-after children are three times more likely to be cautioned or convicted of an offence than others. Accordingly, it is likely that the sample of this study over-represented the prevalence of factors such as abuse and attachment insecurity.

The fact that secondary data was employed was beneficial as it increased the sample size. However, the demographic information obtained from the secondary data was more limited than the one collected by the author, which had an impact on the descriptive statistics performed.

In regard to the methodology used, it is worth acknowledging that, aside from the secondary data, all aspects of this research study were designed and conducted by the author. This includes the hypotheses explored, the procedure used, and the administration and scoring of the interviews. This is likely to have added a certain level of subjectivity to the study. Additionally, the interviews were conducted in the presence of a case worker and this may have had an impact on the level of information disclosed by participants. In future studies, it is advisable that interviews are conducted in private. It is also advisable that interviews are scored by someone blind to the purpose of the research study.

Finally, and despite the fact that the ASI-AD addresses some of the limitations of other attachment measures, this measure is not without its own limitations. Because the ASI-AD is a relatively new measure of attachment, the empirical evidence supporting its reliability and validity is still limited, which may impact on the reliability of the results of this study. Using the ASI-AD also impacted on the qualitative element of this study, due to the questions being semi-structured. To offset this limitation, participants were prompted to expand on their answers and the final qualitative data allowed for a rich process of analysis. Additionally, there is no information on the extent to which the interpersonal characteristics of syndromes such as Asperger's impact on the ratings of the ASI-AD. This may have impacted on the rating of Terry's attachment style.

\section{Recommendations for future research}

Despite the fact that there are some preliminary studies exploring the attachment styles of sexual offenders (eg. Ward et al., ${ }^{32}$ the link 
between specific insecure attachment styles and different sexual offending behaviors has not been consistently found.

This study adds to the literature on adolescent sexual offending. However, further research is needed to continue exploring the mediating effect of insecure attachment styles on the etiology of sexual offending. The results of this study, in particular, identify correlates of sexual offending, not aetiological factors. Further research is needed, employing longitudinal designs. This would assist in establishing causal relationships to determine the developmental trajectories predisposing sexual offending behaviour.

Further research is also needed exploring the link between offender status and attachment styles in adolescent sex offenders, using a UK representative sample. Further research in this area would have significant implications for clinical practice and research, further impacting on recidivism rates of adolescent sexual offenders.

Additionally, a more comprehensive and inclusive approach, incorporating both a control group and a group of violent offenders would be of benefit to the literature, enabling comparisons between groups, and adding to theoretical models of offending behavior. There is also a lack of mixed-methods and qualitative studies in the adolescent sex offender literature. Studies using these designs are needed as they would allow us to obtain a narrative overview of how sexual offending behavior develops, in the context of attachment difficulties.

Finally, the results of this study, despite being tentative, highlight the prevalence of dysfunctional attachments and abuse histories in the background of adolescent sex offenders, further highlighting the need for this client group to be subject not only to criminal justice systems, but also to welfare systems. Further research in this area is of the utmost importance in informing the trajectory of policy, procedures and practice with adolescents who display sexually harmful behavior.

\section{Acknowledgments}

None.

\section{Conflicts of interest}

Author declares sthere are no conflicts of interest.

\section{Funding}

None.

\section{References}

1. Hackett S. What Works for Children and Young People with Harmful Sexual Behaviours. Essex: Barnardo’s. 2004

2. Bifulco A. The Attachment Style Interview for Adolescents (ASI-AD) London: Kingston University. 2012.

3. Ward T, Louden K, Hudson SM, et al. A descriptive model of the offense chain for child abusers. Journal of Interpersonal Violence. 1995;10(4):452-472.

4. Zaremba LA, Keiley MK.. The mediational effect of affect regulation on the relationship between attachment and internalizing/ externalizing behaviours in adolescent males who have sexually offended. Children and Youth Services Review. 2011;33(9):1599-1607.

5. Lowenstein L. Aspects of young sex abusers - A review of the literature concerning young sex abusers (1996-2004). Clinical Psychology and Psychotherapy. 2006;13(1):47-55.

6. Hutton L, Whyte B. Children and young people with harmful sexual behaviours: First analysis of data from a Scottish sample. Journal of Sexual Aggression. 2006;12(2):115-125.
7. Stevens P, Hutchin K, French L, et al. Developmental and offencerelated characteristics of different types of adolescent sex offender: A community sample. Journal of Sexual Aggression. 2013;19(2):138-157,

8. Waite D, Keller A, McGarvey EL, et al. Juvenile sex offender re-arrest rates for sexual, violent nonsexual and property crimes: a 10 year follow-up. Sexual Abuse. 2005;17(3):313-331.

9. Reitzel LR, Carbonell JL. The effectiveness of sexual offender treatment for juveniles as measured by recidivism: A meta-analysis. Sexual Abuse. 2006;18(4):401-421.

10. Richardson G. Sharp practice: The sexually harmful adolescent risk protocol. In Calder MC (Eds.), Sexual abuse assessments: Using and developing frameworks for practice. Dorset: Russell House Publishing, England. 2009;213-227.

11. Worling JR, Litteljohn A, Bookalam D. 20-year prospective follow-up study of specialized treatment for adolescents who offended sexually. Behav Sci Law . 2010;28(1):46-57.

12. Vizard E. Practitioner review: The victims and juvenile perpetrators of child sexual abuse-assessment and intervention. $J$ Child Psychol Psychiatry. 2013;54(5):503-515.

13. Smith C, Allardyce S, Hackett S, et al. Practice and policy in the UK with children and young people who display harmful sexual behaviours: an analysis and critical review. Journal of Sexual Aggression. 2014;20(3):267-280

14. Home Office. Home office guidance to the Probation Service. London. 1999.

15. Masson H. Policy, law and organisational contexts in the United Kingdom. In: Erooga M Masson H (Eds.), Children and young people who sexually abuse others. Abingdon: Routledge, England. 2006.

16. Hackett S, Masson H, Phillips S. Services for young people who sexually abuse. London: NSPCC, Youth Justice Board and National Organisation for the Treatment of Abusers, London. 2005.

17. HM Government. Working together to safeguard children: A guide to interagency working to safeguard and promote the welfare of children. London: DCSF. 2010

18. Boyd NJ, Hagan M, Cho ME. Characteristics of adolescent sex offenders: a review of the research. Aggression and Violent Behavior. 2000;5(2)2:137-146.

19. Davis G, Leitenberg H. Adolescent sex offenders. Psychological Bulletin. 1987;101:417-427.

20. Lewis DO, Shankok SS, Pincus JH. Juvenile sexual assaulters. Am J Psychiatry. 1979;136(9):1194-1196.

21. Van Ness SR. Rape as instrumental violence: A study of youth offenders. Journal of Counseling, Services, and Rehabilitation. 1984;9(1-2):161-170.

22. Bagley C, Shewchuk Dann D. Characteristics of 60 children and adolescents who have a history of sexual assault against others: evidence from a controlled study. Journal of Child and Youth Care. 1991;43-52.

23. Hunter JA, Figueredo AJ, Malamuth NM, et al. Juvenile sex offenders: Towards the development of a typology. Sexual Abuse: A Journal of Research and Treatment. 2003;15(1):27-48.

24. Lane C. Juvenile sexual offending. San Francisco: Jossey-Bass, USA. 1997.

25. Hudson SM, Ward T. Interpersonal competency in sex offenders. Behavior Modification. 2000;24(4):494-527.

26. Langton $\mathrm{C}$, Marshall $\mathrm{W}$. The role of cognitive distortions in relapse prevention programs. In: Laws $\mathrm{D}$, et al. (Eds.), Remaking relapse prevention with sex offenders: A sourcebook. Thousand Oaks, CA SAGE Publications, USA. 2000. p:167-187. 
27. van Wijk A, Vermeiren $R$, Loeber $R$, et al. Juvenile sex offenders compared to non-sex offenders: A review of the literature 1995-2005. Trauma Violence Abuse. 2006;7(4):227-243.

28. Andrade JT, Vincent GM, Saleh FM. Juvenile sex offenders: A complex population. Journal of Forensic Sciences. 2006;51(1):163-167.

29. Becker JV, Hicks SJ. Juvenile sexual offenders: Characteristics, interventions and policy issues. Annals of the New York Academy of Sciences. 2003;989:397-410.

30. Craissati J, McClurg G, Browne K. The parental bonding experiences of sex offenders: A comparison between child abusers and rapists. Child Abuse \& Neglect . 2002;26(9):909-921.

31. Marshall LE, Marshall WL. The role of attachment in sexual offending: An examination of preoccupied-attachment-style offending behavior. In: Schwartz BK (Ed.), The sex offender: Current treatment modalities and systems-issues NJ: Civic Research Institute, Kingston. 2002. p.31-38.

32. Ward T, Hudson SM, Marshall WL. Attachment style in sex offenders: A preliminary study. Journal of Sex Research. 1996;33(1):17-26.

33. Ward T, Hudson SM, Marshall WL, et al. Attachment style and intimacy deficits in sexual offenders: A theoretical framework. Sexual Abuse: $A$ Journal of Research and Treatment. 1995;7(4):317-335.

34. Seto MC, Lalumière ML. What is so special about male adolescent sexual offending? A review and test of explanations through metaanalysis. Psychol Bull. 2010;136(4):526-575.

35. Robertiello G, Terry KJ. Can we profile sex offenders? A review of sex offender typologies. Aggression and Violent Behavior. 2007;12(5):508-518.

36. Miner MH, Romine SR, Robinson BE, et al. Anxious attachment, socia isolation, and indicators of sex drive and compulsivity: predictors of child sexual abuse perpetration in adolescent males? Sexual Abuse. 2014;1-22.

37. Robinson BE, Lewis-Dmello A, Paldron M, et al. Interview assessment of attachment style with adolescent sex offenders: Development and use of the Roots Adolescent Attachment Protocol (RAAP). 2013.

38. Miner M, Robinson B, Knight R, et al. Understanding sexual perpetration against children: effects of attachment style, interpersonal involvement, and hypersexuality. Sexual Abuse: A Journal of Research and Treatment. 2010;22:58-77.

39. Jamieson S, Marshall W. Attachment styles and violence in child abusers. Journal of Sexual Aggression. 2000;5(2):88-98.

40. Marsa F, O'Reilly G, Carr A, et al. Attachment styles and psychological profiles of child sex offenders in Ireland. Journal of Interpersonal Violence. 2004;19:228-251.

41. Smallbone SW, Dadds MR. Childhood attachment and adult attachment in incarcerated adult male sex offenders. Journal of Interpersonal Violence. 1998;13:555-573.

42. Saunders EB, Awad GA, White G. Male adolescent sexual offenders: the offender and the offense. Canadian Journal of Psychiatry. 1986;31:542-549.

43. Hendriks J, Bijleveld CC. Juvenile sexual delinquents: Contrasting child abusers with peer abusers. Criminal Behaviour and Mental Health. 2004;14(4):238-250.

44. Gunby C, Woodhams J. Sexually deviant juveniles: Comparisons between the offender and offence characteristics of 'child abusers' and 'peer abusers'. Psychology, Crime and Law. 2010;16(2):47-64.

45. Worling, JR. Adolescent sex offenders against females: differences based on age of their victims. International Journal of Offender Therapy and Comparative Criminology. 1995;393:276-293.
46. Wilde GJS. Neurotische labiliteit gemeten volgens de vragenlijstmethode. De Amsterdamse Biografische Vragenlijst (Neurotic lability measured through the questionnaire method. The Amsterdam Biographical Questionnaire). Amsterdam: Van Rossen. 1970.

47. Achenbach TM.Integrative guide for the 1991 CBCL/4-18, YSR and TRF profiles. Burlington: Department of Psychiatry, University of Vermont. 1991.

48. Lawson JS, Marshall WL, McGrath P. The Social Self-Esteem Inventory. Educational and Psychometric Measurements. 1979;39:803-811.

49. Raid GH, Fitts WH. Tennessee Self-Concept Scale: Revised manual. Los Angeles: Western Psychological Services. 1988.

50. Hunter JA, Hazelwood RR, Slesinger D. Juvenile perpetrated sex crimes: Patterns of offending and predictors of violence. Journal of Family Violence. 2000;15(1):81-93.

51. George Hsu LK, Starzynski J. Adolescent rapists and adolescent sexual assaulters. International Journal of Offender Therapy and Comparative Criminology. 1990;34(1):23-30.

52. Rubinstein M, Yeager C, Goodstein C, et al. Sexually assaultive male juveniles. A follow-up. American Journal of Psychiatry. 1993; 150:262-265.

53. Hanson RK, Bussiere MT. Predicting relapse: A meta-analysis of sexual offender recidivism studies. Journal of Consulting and Clinical Psychology. 2005;66(2):348-362.

54. Watkins B, Bentovim A. The sexual abused of male children and adolescents: a review of current research. Journal of Child Psychology and Psychiatry. 1992;33:197-248.

55. Ward T, Beech AR. An integrated theory of sexual offending. Aggression and Violent Behavior. 2006;11:44-63.

56. Ward T, Siegert RJ. Toward and comprehensive theory of child sexual abuse: A theory knitting perspective. Psychology, Crime, and Law. 2002;9:319-351.

57. Medoff D. Developmental considerations in the forensic assessment of adolescent sexual offenders. The Forensic Examiner. 2004;13:26-30.

58. Bumby K. Understanding treatment for adults and juveniles who have committed sex offenses. 2006.

59. Caldwell MF. Study characteristics and recidivism base rates in juvenile sex offender recidivists. International Journal of Offender Therapy and Comparative Criminology. 2010;54(2):197-212.

60. Righthand S, Welch C. Juveniles who have sexually offended: A review of the professional literature. Office of Juvenile Justice and Delinquency Prevention. 2001

61. Alexander MA. Sexual offender treatment efficacy revisited. Sexual Abuse. 1999;11(2):101-116.

62. Knopp FH. The youthful sex offender: the rationale and goals of early intervention and treatment Syracuse, Safer Society Press, New York, USA. 1985.

63. Wind TE. The quandary of Megan's Law: When the child sex offender is a child. John Marshall Law Review. 2003;37:73-103.

64. Greene JC, Caracelli VJ, Graham WF. Toward a conceptual framework for mixed-method evaluation designs. Educational Evaluation and Policy Analysis. 1989;11(3):255-274.

65. Qayum A. Exploring the link between early attachment styles and maladaptive schemas in juvenile sexual offenders (Unpublished doctoral thesis). University of Birmingham, Birmingham, USA. 2014.

66. Bifulco A, Moran PM, Ball C, et al. Adult attachment style I: Its relationship to clinical depression. Social Psychiatry and Psychiatric Epidemiology. 2002;37(2):50-59. 
67. Ritchie J, Spencer L. Qualitative data analysis for applied policy research. In: Bryman A \& Burgess RG (Eds.), Analyzing qualitative data, Routledge, New York, USA. 1994. p.173- 194.

68. World Health Organization. The ICD-10 classification of mental and behavioural disorders: clinical descriptions and diagnostic guidelines. 1992.

69. Marshall WL. The treatment of sex offenders: What does the outcome data tell us? A reply to Quinsey, Harris, Rice, and Lalumière. Journal of Interpersonal Violence . 1993;8:524-530.

70. Baim C, Morrison T. Attachment based practice with adults, Understanding strategies and promoting positive change. Pavilion publishing, Brighton, USA. 2011.

71. Keijsers GPJ, Schaap C, Hoogduin K, et al. The therapeutic relationship in the behavioural treatment of anxiety disorders. Behavioral Psychotherapy. 1991;19(4):359-367.

72. Dozier M. Attachment organisation and treatment use for adults with serious psychopathological disorders. Development and Psychotherapy. 1990;2:47-60.

73. Scott-Brown L, Wright J. The relationship between attachment strategies and psychopathology in adolescence. Psychology and Psychotherapy: Theory, Research and Practice. 2003; 76:351-367.

74. Rich P. Attachment and sexual offending. Wiley, West Sussex, UK. 2006.

75. Goocher BE. Some comments on the residential treatment of juvenile sex offenders. Child and Youth Care Forum. 1994;23(4):243-250.

76. Borduin CM, Henggeler SW, Blaske DM, et al. Multisystemtic treatment of adolescent sexual offenders. International Journal of Offender Therapy and Comparative Criminology. 1990;34:105-113.
77. Letourneau EJ, Henggeler SW, Borduin CM, et al. Multisystemic therapy for juvenile sexual offenders: 1-year results from a randomized effectiveness trial. Journal of Family Psychology. 2009;23:89-102.

78. Hunter JA Jr, Figueredo AJ. Factors associated with treatment compliance in a population of juvenile sexual offenders. Sexual Abuse: A Journal of Research and Treatment. 1999;11(1):49-67.

79. Trivits LC, Reppucci DN. Application of Megan's Laws to juveniles. American Psychologist . 2002;57:690-704.

80. Caldwell MF, Dickinson C. Sex offender registration and recidivism risk in juvenile sexual offenders. Behavioral Sciences and the Law. 2009;27(6):941-956.

81. Hobbs GF, Hobbs CJ, Wynne JM. Abuse of children in foster and residential care. Child Abuse and Neglect. 1999;23(12):1239-1252.

82. Iwaniec D. The child's journey through care: placement stability, care planning and achieving permanency. Chichester: John Wiley, Queen's University, Belfast, Ireland. 2006.

83. McAuley C. Pathways and outcomes: A ten year follow-up of children who have experienced care. Belfast: Department of Health, Social Services, and Public Safety. 2004.

84. McAuley C, Pecora P, Rose W. Enhancing the well-being of children and families through effective interventions: Evidence for practice. Jessica Kingsley Publishers, London, UK. 2006. 